\title{
Effect of Alkali Metal on Gasification of Coke
}

\author{
J.M. Yang \\ School of energy power and mechanical engineering \\ North China Electric Power University \\ Baoding, China
}

B. Du

School of energy power and mechanical engineering

North China Electric Power University

Baoding, China

\author{
J.N. Xu \\ School of energy power and mechanical engineering \\ North China Electric Power University \\ Baoding, China
}

\begin{abstract}
This paper adopted the thermogravimetric analyzer, studied on the gasification reactivity of Xinjiang Zhundong coal. Researched gasification reactivity of different coal samples such as demineralized coal and coke with catalyst. Studied the influence of alkali metal on coke gasification process. After excluded the interference of ash, the same amount of catalyst $\mathrm{NaCl}$ and catalyst $\mathrm{NaOH}$ were added to samples, then compared the TGA in the two conditions. The results show that: the catalytic effect of alkali metal is reducing the gasification reaction energy, prolonging the time that the reaction rate reaching the maximum level, furthermore find that catalytic effect of $\mathrm{NaCl}$ is better than the catalytic effect of $\mathrm{NaOH}$.
\end{abstract}

Keywords-coke gasification; catalys; thermogravimetric analysis; alkali metal

\section{INTRODUCTION}

Coal gasification is a kind of technology in comprehensive utilization of clean coal, it is the foundation of coal chemical industry, hydrogenation process and coal liquefaction. To a great extent, gasification process affects the cost and the efficiency of chemical products. Therefore the research and development of coal gasification technology with high efficiency, low consumption and no pollution is the precondition of comprehensive utilization of coal and coal chemical industry[1]. Coal gasification is a thermal chemical reaction process, including pyrolysis and gasification two parts. Gasification process contains a series of complicated physical and chemical changes. Reactions mainly include coal pyrolysis, gasification and combustion[2]. Because of the coal is a kind of complex mixtures, there are many factors can influence its gasification, including coal properties, mineral in coal, pressure and temperature[3]. In the coal gasification process, alkali metals mainly play a catalytic role. Other study shows that alkali metals have influence both on pyrolysis stage and gasification stage[4].

\section{EXPERIMENTAL PROCESS}

\section{A. Preparation of the Experiment Material}

Xinjiang Zhundong coal is adopted in the experiment, industry analysis and

elemental analysis of the coal sample are listed in the table:
TABLEI. PRoXimate ANALysis AND ElEMENTAL ANALysis OF CoAL SAMPLE

\begin{tabular}{ccccccccc}
\hline \multicolumn{4}{l}{ proximate analysis (wt/\%) } & \multicolumn{4}{c}{ elemental analysis(wt/\%) } \\
\hline $\mathrm{M}_{\mathrm{ad}}$ & $\mathrm{A}_{\mathrm{d}}$ & $\mathrm{V}_{\mathrm{daf}}$ & $\mathrm{FC}_{\mathrm{ar}}$ & $\mathrm{C}_{\mathrm{d}}$ & $\mathrm{H}_{\mathrm{d}}$ & $\mathrm{N}_{\mathrm{d}}$ & $\mathrm{O}_{\mathrm{d}}$ & $\mathrm{S}_{\mathrm{t}, \mathrm{d}}$ \\
9.21 & 6.99 & 32.35 & 50.59 & 74.13 & 3.90 & 0.83 & 13.60 & 0.55 \\
\hline
\end{tabular}

The preparation of coke sample:

Washing: prepare $30 \mathrm{~g}$ coal, add 600ml distilled water, put on a magnetic stirrer, stir $6 \mathrm{~h}$ in water at the temperature of $30^{\circ} \mathrm{C}$, filter, dry in a drying box at the temperature of $110^{\circ} \mathrm{C}$ for $8 \mathrm{~h}$. Then take $15 \mathrm{~g}$ washed coal, add $300 \mathrm{ml}$ dilute hydrochloric acid, put on the stirrer, stir $6 \mathrm{~h}$ in water at the temperature of $60^{\circ} \mathrm{C}$, dry at the temperature of $110^{\circ} \mathrm{C}$ for $8 \mathrm{~h}$, wash to neutral with deionized water.

Pickling: prepare $50 \mathrm{~g}$ coal in a beaker, add $300 \mathrm{ml}$ concentrated hydrochloric acid (38\%), put the beaker in water at constant temperature of $60^{\circ} \mathrm{C}$, put on the stirrer and stir for $2 \mathrm{~h}$, add $300 \mathrm{ml}$ hydrofluoric acid $(\geq 40 \%)$ in the filtrated coal samples. According to the above method, repeat heating process and filtering process, wash samples with deionized water repeatedly, until reach the detectable limit of Cl-. Dry samples in the drying box for $8 \mathrm{~h}$, then get the demineralized coals.

Add $\mathrm{NaCl}, \mathrm{NaOH}$ : put the demineralized coal samples into two beakers each $10 \mathrm{~g}$, add $50 \mathrm{ml} \mathrm{NaCl}$ solution (5wt/\%) and $50 \mathrm{ml} \mathrm{NaOH}$ solution (5wt/\%) respectively, stir with a glass rod from time to time, after 24 hours, filter the solutions, dry the samples in the drying box for $8 \mathrm{~h}$, then get the coke carried $\mathrm{NaCl}$ and $\mathrm{NaOH}$.

\section{A. Experimental Steps}

Take $10 \mathrm{mg}$ coal sample, heat the coal sample to $850^{\circ} \mathrm{C}$ at the heating rate of $50^{\circ} \mathrm{C} / \mathrm{min}$ and keep the constant temperature for $15 \mathrm{~min}$. In the entire process, the flow rate of the reaction gas CO2 (purity is $99.99 \%$ ) is $120 \mathrm{ml} / \mathrm{min}$, the flow rate of balance room protective gas $\mathrm{N} 2(99.99 \%$ purity) is $20 \mathrm{ml} / \mathrm{min}$. The weight loss curves of the reaction process (TG) and the rate of weight loss curve (DTG) are collected by the computer automatically. Experiments on coke carried $\mathrm{NaCl}$ and $\mathrm{NaOH}$ are carried out with reference to the above experimental procedures. 


\section{PROCESS AND ANALYSIS OF EXPERIMENTAL RESULTS}

\section{A. Demineralized Coal Thermal Gravimetric Analysis}

The first set of experiments with the demineralized coal was studied by thermogravimetric analysis. The left side of the ordinate curve (weightlessness line) represents the weight percentage of the remaining, the right side of ordinate curve (differential line) is expressed by the speed of the weight loss. The abscissa represents time ( $\mathrm{min})$.

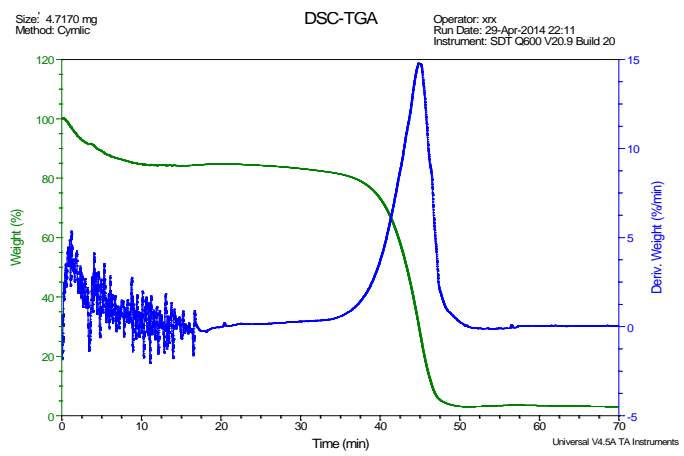

FIGURE I. TGA OF DEMINERALIZED COAL

\section{B. Effect of Sodium Catalyst On Coke Gasification}

The second set of experiments obtains the coke carried catalyst $\mathrm{NaCl}$ thermogravimetric analysis results.
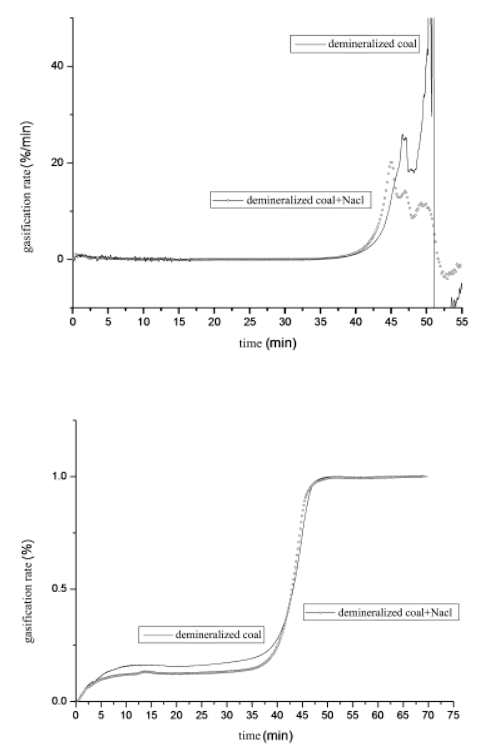

FIGURE II. GASIFICATION RATE AND CONVERSION RATE OF COKE SAMPLE CARRIED NACL

It can be seen from the curves, comparing coke carried sodium catalyst with coal sample without catalyst, in the beginning of the gasification reaction, coke sample carried sodium catalyst reacts significantly earlier than coke without catalyst. This is because the catalyst lowers the energy required for reaction. As the reaction proceeding, conversion degree of demineralized coal is higher than that of the coke sample carried catalyst. After 42 minutes, coke sample carried catalyst reaches the highest conversion degree more quickly. Overall, the coke sample carried catalyst needs less time to complete the gasification reaction than coal sample without catalyst. According to the image of the gasification rate changing with time, the coke sample carried $\mathrm{NaCl}$ reaches the maximum reaction rate earlier than the demineralized coal obviously. So it can be seen that $\mathrm{NaCl}$ is a good catalyst in the coke gasification reaction, moreover the whole reaction is relatively flat. In the third experiment, prepare the same amount of coke sample as the second one, add a different form of alkali metal $\mathrm{NaOH}$ and repeat the experiment, then get the coke carried $\mathrm{NaOH}$ thermogravimetric analysis results.
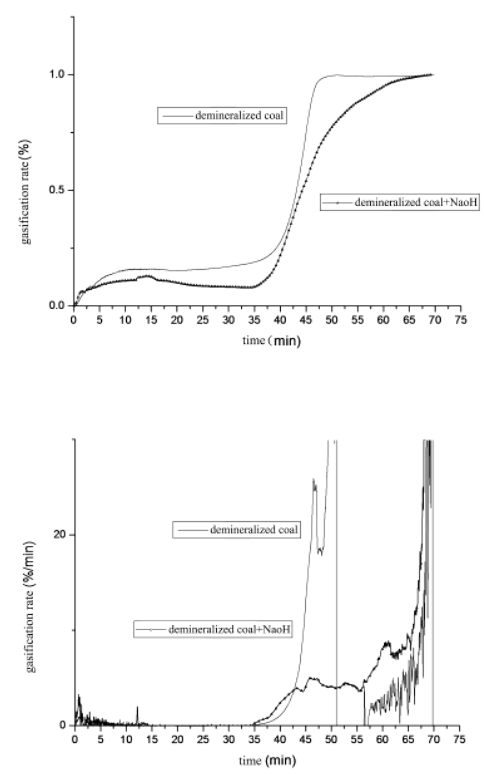

FIGURE III.

\section{GASIFICATION RATE AND CONVERSION RATE OF COKE SAMPLE CARRIED NAOH.}

Conclusion of the experiment is similar to that of the experiment carried out by coke with $\mathrm{NaCl}$. The presence of alkali metal can reduce the activation energy of reaction. In pyrolysis stage and gasification stage, alkali metals have different catalytic effects. In the pyrolysis stage, alkali metals inhibit the graphitization process of coke, reduce the pyrolysis reaction energy and promot the reaction; In the gasification stage, alkali metals reduce the gasification reaction energy and prolong the time of the maximum rate of reaction.

C. Comparative analysis of $\mathrm{NaCl}$ and $\mathrm{NaOH}$ catalytic effect

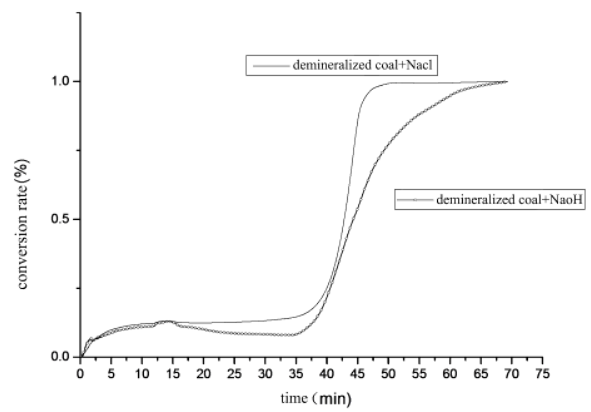




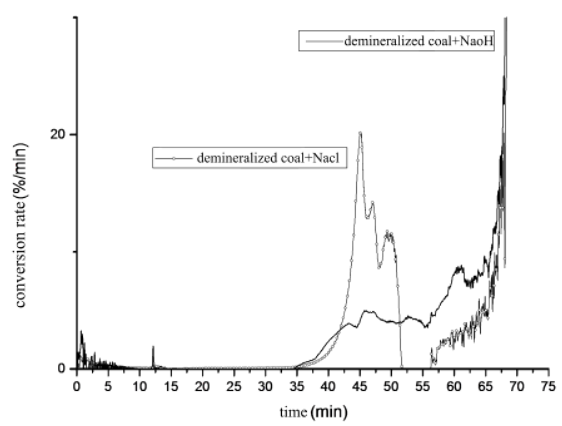

FIGURE IV.

GASIFICATION RATES AND CONVERSION RATES OF TWO CONDITIONS

By studying conversion rate changing with time, conversion rate of coke carried $\mathrm{NaCl}$ is higher than that of coke carried $\mathrm{NaOH}$ in each time, and the experiment on coke carried $\mathrm{NaCl}$ complete faster. From the perspective of gasification rate, in the early stage of the reaction, the both two experiments are relatively slow. This is because the temperature of reactions does not reach a very high level in initial stage. As the temperature increasing gradually, the catalytic effect gets further strengthened, the gasification rate of two samples improves significantly. But in most time, gasification rate of coke carried $\mathrm{NaCl}$ is much higher and the gap of rate is obvious. Particularly in second half of reaction, the gasification rate of coke carried $\mathrm{NaOH}$ is slower than that of the sample without any catalyst. This may be owning to catalyst $\mathrm{NaOH}$ damages the microcrystalline structure of coke which makes the reaction difficult. In the early stage of reaction, $\mathrm{NaOH}$ has better catalytic effect, while from perspective of the whole reaction, the catalytic effect of $\mathrm{NaCl}$ on coke gasification is better.

\section{CONCLUSION}

The experiment adopts thermogravimetric analyzer, excluding the interference of ash in coal, the same amount of catalyst $\mathrm{NaCl}$ and catalyst $\mathrm{NaOH}$ are added to samples. Analyse the results of different experiments, in the gasification stage, the catalytic effect of alkali metal is reducing the gasification reaction energy, prolonging the time that reaction rate reaching the maximum level. The maximum reaction rate of coke carried $\mathrm{NaCl}$ is two times more than the rate of coke carried $\mathrm{NaOH}$, and the gasification rate of two samples are higher than the rate of coal sample without catalyst. While in the second half of gasification, reaction rate of coke carried $\mathrm{NaOH}$ is less than the reaction rate of demineralized coal. Finally conclude that catalytic effect of $\mathrm{NaCl}$ is better than the effect of $\mathrm{NaOH}$.

\section{REFERENCES}

[1] Chen Guoyan, Kinetic analysis of coke gasification reaction. Boiler technology, 43(1), pp. 72-76, 2012.

[2] Guo Shucai, Coal chemical engineering. Metallurgical Industry Press: Beijing, pp. 205-249, 1991.

[3] Gao Suping, The analysis process and the factors influencing the gasification reaction. Science and Education Frontier, 27, pp. 37-51, 2011
[4] Xiong Jie, Zhou Zhijie, Xu Shenqi, Yu Guangsuo. The influence of alkali metal on coal pyrolysis and gasification reaction. Journal of chemical industry and Engineering, 62(1), pp. 192-198, 2011. 